\title{
DEHYDRATION OF WATER MOLECULE IN AMORPHOUS CALCIUM PHOSPHATE
}

\author{
Y. KOJIMA, K. SAKAMA, T. TOYAMA, T. YASUE and Y. ARAI \\ Department of Industrial Chemistry, Faculty of Science and Engineering, \\ Nihon University, 1-8, Kanda-Surugadai, Chiyoda-ku, Tokyo 101, Japan
}

\begin{abstract}
Amorphous calcium phosphate (ACP) was synthesized by dropping rapidly aqueous ammonia into calcium dihydrogenphosphate monohydrate $\left(\mathrm{Ca}\left(\mathrm{H}_{2} \mathrm{PO}_{4}\right)_{2} \bullet \mathrm{H}_{2} \mathrm{O}, \mathrm{MCP}\right)$ solution. The composition of $\mathrm{ACP}$ was given within the wide range of $\mathrm{Ca} / \mathrm{P}$ atomic ratio $1.25 \sim 1.55$ and was distinguished to three kinds (H-ACP, M-ACP and L-ACP) by different $\mathrm{Ca} / \mathrm{P}$ atomic ratios. Thermal behavior of water molecule in three types of ACP was investigated by X-ray diffraction, thermal analysis (TG-DTA) and Fourier transformation infrared spectroscopy (FTIR). Two kinds, the water molecule in ACP existed adsorbed water and bound water. Distinction of these water molecules was possible from Arrehenius plot by relating between heating rates $(\beta)$ and upper temperature of endothermic peaks (Tm) with thermal analysis (TG-DTA). The activation energy for dehydration of adsorbed water and bound water until about $125{ }^{\circ} \mathrm{C}$ was able to determine from the gradient of Arrehenius plot. For example, the activation energy for dehydration of bound water in H-ACP of high calcium type $(\mathrm{Ca} / \mathrm{P}$ atomic ratio 1.55) was $26.4 \mathrm{kcal} / \mathrm{mol}$. It was considered that bound water was stabilized by increasing $\mathrm{Ca} / \mathrm{P}$ atomic ratio in $\mathrm{ACP}$.
\end{abstract}

\section{$\underline{\text { INTRODUCTION }}$}

The authors have been conducting a series of studies on synthesis of amorphous calcium compound and its characteristics $^{1-8)}$. Amorphous calcium phosphate (ACP) forms a part unstable precursor of biomineral in vivo, and it has been known finally crystallizing to hydroxyapatite (HAp) of low crystalline ${ }^{9)}$ 13). The synthesis of ACP was already achieved by liquid phase reactions of rapid mixture method ${ }^{14)}$ and sol-gel method ${ }^{15)}$. The

$\overline{\text { Received October 16, 1994; Accepted December 9, } 1994}$ 
composition and structure of ACP have been reported until now. That is, ACP was constituted of spherical cluster of $9.5 \AA$ in diameter with composition of $\mathrm{Ca}_{9}\left(\mathrm{PO}_{4}\right)_{6}$ by $\mathrm{X}$ ray reduced radial distribution technique ${ }^{16)-18)}$. However, thermal behavior of water molecule in three types ACP was still involved many problems to be solved.

The authors have been conducting a series of studies on synthesis of ACP by dropping rapidly aqueous ammonia into calcium dihydrogenphosphate monohydrate (MCP) solution $^{6-8)}$. As a previous result, ACP, obtained by controlling condition of hydrolysis reaction of $\mathrm{MCP}$, was distinguished to two kinds by different $\mathrm{Ca} / \mathrm{P}$ atomic ratios ${ }^{7}$. Furthermore, this paper was investigated in detail on the kind of ACP. ACP could be distinguished into three types from crystallization of ACP in mother liquor, L-ACP(low calcium type, $\mathrm{Ca} / \mathrm{P}$ atomic ratio: $1.25 \sim 1.32$ ), $\mathrm{M}-\mathrm{ACP}$ (medium calcium type, $\mathrm{Ca} / \mathrm{P}$ atomic ratio: $1.34 \sim 1.40$ ) and $\mathrm{H}-\mathrm{ACP}$ (high calcium type, $\mathrm{Ca} / \mathrm{P}$ atomic ratio: $1.43 \sim 1.55$ ) for convenience.

Studies were made to investigate synthetic conditions of the above three types ACP, distinction of adsorbed water and bound water in ACP and activation energy for dehydration of these water molecules.

\section{EXPERIMENTAL}

\section{MATERIALS}

$\operatorname{MCP}\left(\mathrm{Ca}\left(\mathrm{H}_{2} \mathrm{PO}_{4}\right)_{2} \cdot \mathrm{H}_{2} \mathrm{O}\right)$ and aqueous ammonia $\left(\mathrm{NH}_{4} \mathrm{OH}\right)$ used for synthesizing ACP, were special-grade reagents supplied by Kanto Chemical Co., Ltd. The purity was about $98 \%$ for MCP and $29 \% \mathrm{NH}_{3}$ for aqueous ammonia.

\section{EXPERIMENTAL METHOD}

The MCP solution $\left(0.005 \sim 0.07 \mathrm{~mol} \cdot \mathrm{dm}^{-3}\right)$ was kept at $0^{\circ} \mathrm{C}$, and aqueous ammonia $(0.1$ $\left.\sim 15 \mathrm{~N} \mathrm{NH}_{4} \mathrm{OH}\right)$ was added quickly to the solution in the specified volume ratio (MCP/NH ${ }_{4} \mathrm{OH}: 80 / 1 \sim 2 / 1$, addition rate: $40 \mathrm{~cm}^{3} \cdot \mathrm{min}^{-1}$ ) ranging from $\mathrm{pH} 6$ to 12 , and gelatinous precipitate formed. The gel was separated from the mother liquor by filtering through a G5 glass filter and it was washed with cold aqueous ammonia and acetone. ACP was given by drying under reduced pressure for $30 \mathrm{~min}$ with air passing through silica gel.

Thermal behavior of water molecule in three types ACP was determined by using X-ray diffraction, thermal analysis (TG-DTA), FT-IR and chemical analysis. The quantity of Ca and $\mathrm{P}$ were measured with ion chromatography (Toa Denpa Kogyo Co., Ltd.) with a column (PCI-305S). 
RESULTS AND DISCUSSION

FORMATION REGIONS OF AMORPHOUS

\section{CALCIUM PHOSPHATE}

$\mathrm{ACP}$ was synthesized at $0{ }^{\circ} \mathrm{C}$ and $\mathrm{Ca} / \mathrm{P}$ atomic ratio in the ACP was affected remarkably by concentration of $\mathrm{MCP}$ solution and $\mathrm{pH}$. ACP was distinguished into three types by different $\mathrm{Ca} / \mathrm{P}$ atomic ratios.

That is, L-ACP was crystallized to dicalcium hydrogenphosphate dihydrate (DCPD) by aging in mother liquor for long time, while $M$ ACP and H-ACP were crystallized to octacalcium phosphate (OCP) and HAp, respectively.

Figure 1 illustrates the effect of concentration of MCP solution and $\mathrm{pH}$ on formation regions of three types $\mathrm{ACP}$ by different $\mathrm{Ca} / \mathrm{P}$ atomic ratios. $\mathrm{L}-\mathrm{ACP}$ was formed at $\mathrm{pH}$ 6 8 under high concentration of MCP solution. M-ACP was obtained at $\mathrm{pH}$ 7 10, but concentration of MCP solution did not take part in the formation region and $\mathrm{H}$ ACP was formed at high $\mathrm{pH} \quad 8 \sim 12$ and low concentration of MCP solution. The border of three types ACP were indicated mixture regions of two types ACP.

\section{INFRARED ABSORPTION SPECTRA OF}

\section{AMORPHOUS CALCIUM PHOSPHATE}

When the atomic structure analysis of three types ACP was carried out by X-ray reduced radial distribution technique, the patterns of ACP's were indicated regular intervals at interatomic distance below $10 \AA$ but was irregular intervals at the above $10 \AA$. These results were characterized by property of amorphous substance ${ }^{16)-18)}$. However, the difference of three types ACP was not

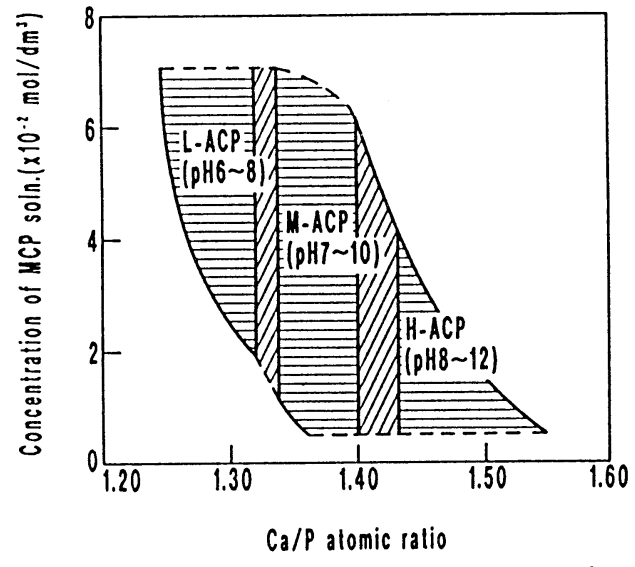

Fig. 1 Effect of concentration of MCP solution and $\mathrm{pH}$ on composition of amorphous calcium phosphate.

Temperature $\left({ }^{\circ} \mathrm{C}\right): 0$

$\mathrm{MCP} / \mathrm{NH}_{4} \mathrm{OH}$ volume ratio

$: 100 / 0.5 \sim 100 / 20$

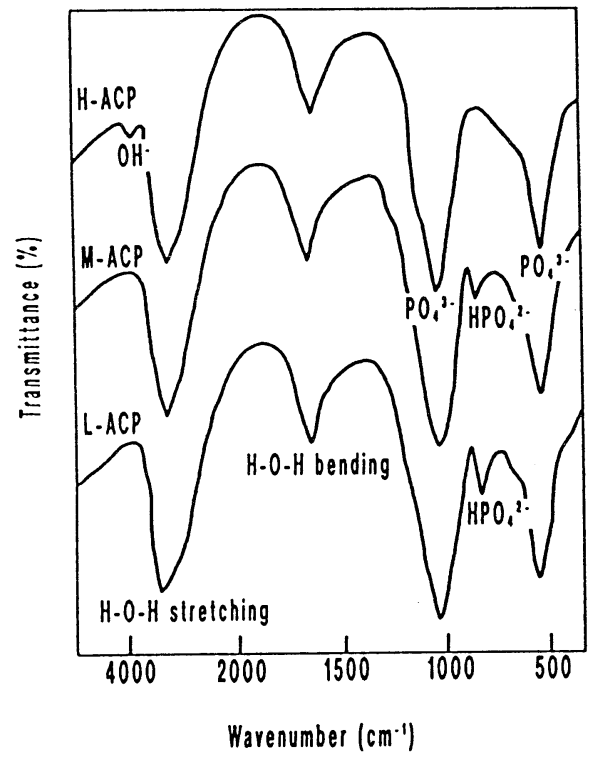

Fig.2 Infrared absorption spectrum of amorphous calcium phosphate. $\mathrm{L}-\mathrm{ACP}(\mathrm{Ca} / \mathrm{P}$ atomic ratio: 1.27$)$ $\mathrm{M}-\mathrm{ACP}(\mathrm{Ca} / \mathrm{P}$ atomic ratio: 1.34$)$ $\mathrm{H}-\mathrm{ACP}(\mathrm{Ca} / \mathrm{P}$ atomic ratio: 1.51$)$ 
confirmed from X-ray reduced radial distribution technique. Infrared absorption spectra of these ACP were also compared.

Figure 2 illustrates infrared absorption spectra of three types ACP. Only H-ACP in three types was observed spectrum at around $3860 \mathrm{~cm}^{-1}$ assigned to stretching vibration of the $\mathrm{O}-\mathrm{H}$ group. The peak spectrum at $860 \mathrm{~cm}^{-1}$ assigned to $\mathrm{HPO}_{4}{ }^{2-}$ group increased with decreasing $\mathrm{Ca} / \mathrm{P}$ atomic ratio in $\mathrm{ACP}$. However, the spectrum of adsorbed water assigned to bending vibration of $\mathrm{H}-\mathrm{O}-\mathrm{H}$ and bound water assigned to stretching vibration of $\mathrm{O}-\mathrm{H}$ were not observed clear difference. So that thermal behavior of water molecule in ACP was investigated by thermal analysis (TG-DTA).

\section{ACTIVATION ENERGY FOR DEHYDRATION OF AMORPHOUS CALCIUM PHOSPHATE}

TG-DTA curves of three types ACP are shown in Figure 3. It was observed that a large endothermic peak with upper temperature at around $115^{\circ} \mathrm{C}$ was resulted from dehydration of water molecule in ACP. The weight loss for dehydration in TG curve slowly

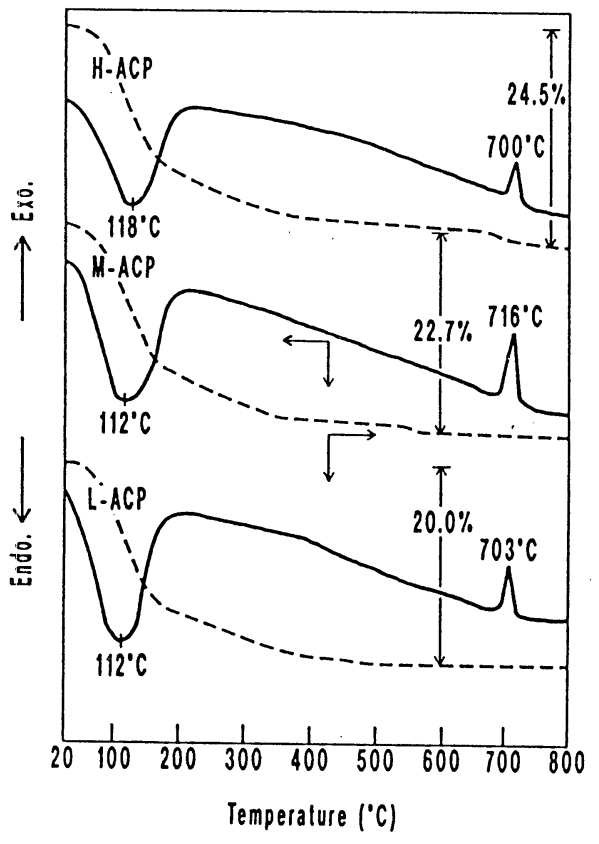

Fig.3 TG-DTA curve of amorphous calcium phosphate.

$\mathrm{L}-\mathrm{ACP}(\mathrm{Ca} / \mathrm{P}$ atomic ratio: 1.27$)$

$\mathrm{M}-\mathrm{ACP}(\mathrm{Ca} / \mathrm{P}$ atomic ratio: 1.34$)$

$\mathrm{H}-\mathrm{ACP}(\mathrm{Ca} / \mathrm{P}$ atomic ratio: 1.51$)$

Heating rate $\left({ }^{\circ} \mathrm{C} / \mathrm{min}\right): 10$

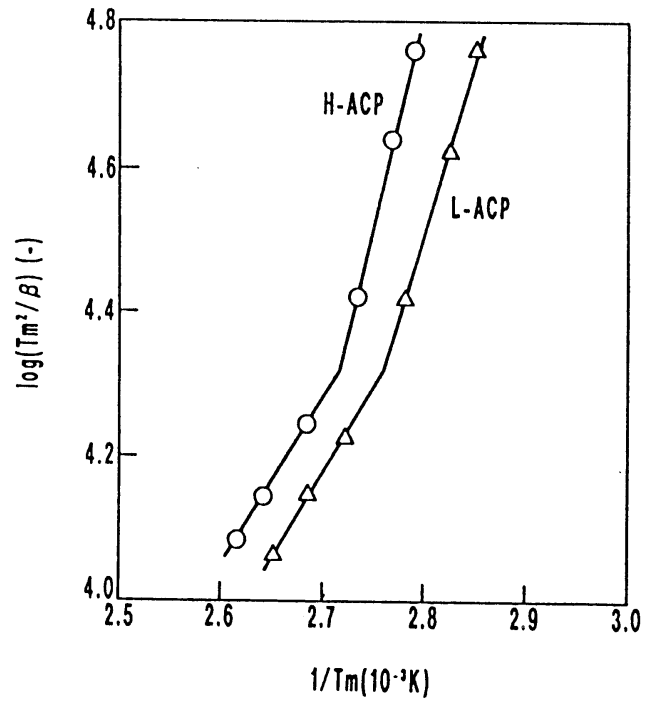

Fig.4 Arrehenius plot for dehydration of amorphous calcium phosphate. $\beta$ : Heating rate, Tm: Temperature of dehydration peak L-ACP(Ca/P atomic ratio: 1.27$)$ $\mathrm{H}-\mathrm{ACP}(\mathrm{Ca} / \mathrm{P}$ atomic ratio: 1.51$)$ 
continued until about $600{ }^{\circ} \mathrm{C}$ and increased with increasing $\mathrm{Ca} / \mathrm{P}$ atomic ratio. For example, that of H-ACP was about $24.5 \%$. But this endothermic peak was considered to overlappe adsorbed water and bound water in ACP. Also a exothermic peak at $700{ }^{\circ} \mathrm{C}$ was resulted from crystallization ACP to $\beta$-TCP.

The water molecule in ACP was known to exist two kinds of adsorbed water and bound water ${ }^{19)}$. Distinction of these water molecule were possible from Arrehenius plot by relating between heating rate $(\beta)$ and upper temperature $(\mathrm{Tm})$ of the endothermic peak at about $120^{\circ} \mathrm{C}$ with thermal analysis ${ }^{19}$. The activation energy for dehydration of bound water in three types ACP was changed by condition of bonding strength. As shown in Figure 4, Arrehenius plot presented by two straight line segments. Although two types of water molecule was often confused, they should be distinguished. The straight line of the large gradient means the dehydration of bound water and small gradient was that of adsorbed water. The adjoining point of two straight lines was indicated starting temperature for dehydration of bound water. That is, the dehydration of bound water was started at above the adjoining point. For example, the temperature of adjoining point was higher H-ACP than L-ACP. The gradient of adsorbed water segment against the point was much the same both L-ACP and H-ACP, but the gradient of slope in bound water segment was bigger H-ACP than L-ACP. The activation energy was determined from this gradient ${ }^{19)}$.

From the above results, Table 1 shows temperature, quantity and activation energy for dehydration of adsorbed water and bound water. The starting temperature for dehydration of bound water shifted toward high temperature with increasing $\mathrm{Ca} / \mathrm{P}$ atomic ratio and quantity of bound water increased. For example, the activation energy for dehydration of bound water were $26.4 \mathrm{kcal} / \mathrm{mol}$ for $\mathrm{H}-\mathrm{ACP}(\mathrm{Ca} / \mathrm{P}$ atomic ratio 1.55$)$ and $10.5 \mathrm{kcal} / \mathrm{mol}$ for L-ACP ( $\mathrm{Ca} / \mathrm{P}$ atomic ratio 1.25$)$, respectively. It was considered that bound water was stabilized by increasing $\mathrm{Ca} / \mathrm{P}$ atomic ratio.

Table 1 Activation energy for dehydration of amorphous calcium phosphate.

\begin{tabular}{|c|c|c|c|c|}
\hline & & H-ACP & M-ACP & L-ACP \\
\hline \multicolumn{2}{|c|}{ Starting temperature for dehydration of bound water $\left({ }^{\circ} \mathrm{C}\right)$} & $100.6 \pm 6.0$ & $96.4 \pm 1.8$ & $89.5 \pm 3.5$ \\
\hline \multicolumn{2}{|l|}{ Adsorbed water $(w t \%)^{*}$} & $8.0 \sim 11.0$ & $5.0 \sim 8.0$ & $5.0 \sim 7.0$ \\
\hline \multicolumn{2}{|l|}{ Bound water $(w t \%)^{* *}$} & $13.0 \sim 16.0$ & $13.0 \sim 14.0$ & $11.0 \sim 13.0$ \\
\hline \multirow{2}{*}{$\begin{array}{l}\text { Activation energy for } \\
\text { dehydration }\end{array}$} & (Adsorbed water $(\mathrm{kcal} / \mathrm{mol})^{*}$ & $10.3 \sim 24.7$ & $10.3 \sim 10.5$ & $8.6 \sim 10.5$ \\
\hline & Bound water $(\mathrm{kcal} / \mathrm{mol})^{* * *}$ & $22.0 \sim 26.4$ & $15.8 \sim 25.2$ & $10.5 \sim 13.7$ \\
\hline
\end{tabular}

${ }^{*}: 25 \sim 94^{\circ} \mathrm{C},{ }^{* *}: 94 \sim 600^{\circ} \mathrm{C},{ }^{* * *}: 94 \sim 125^{\circ} \mathrm{C}$ 
Therefore, the border temperature of adsorbed water and bound water in ACP were possible to determine from Arrehenius plot by relating between $\beta$ and Tm. It was confirmed that quantity of water molecule and stability of bound water by increasing $\mathrm{Ca} / \mathrm{P}$ atomic ratio in ACP were differed.

\section{REFERENCE}

1) T.Yasue, A.Mamiya, Y.Takahashi, R.Tsukisaka and Y.Arai, J. Chem. Soc. Jpn., 1984, 1107.

2) T.Yasue, A.Mamiya, Y.Takahashi, T.Fukushima and Y.Arai, Sekko to Sekkai, No. 198, 3 (1985).

3) T.Yasue, K.Kanai, Y.Kojima and Y.Arai, J. Ceram. Soc. Japan, 100, 1053 (1992).

4) Y.Kojima, A.Kawanobe, T.Yasue and Y.Arai, J. Ceram. Soc. Japan, 101, 1145 (1993).

5) Y.Kojima, A.Kawanobe, T.Yasue and Y.Arai, J. Ceram. Soc. Japan, 102, in press.

6) T.Yasue, J.Sakakida, A.Yoshiyama and Y.Arai, Sekko to Sekkai, No.229, 3 (1991).

7) T.Yasue, A.Yoshiyama and Y.Arai, Phospho. Res. Bull., 1, 27 (1991).

8) T.Yasue, Y.Kojima, A.Yoshiyama and Y.Arai, Phos. Sulf. Silicon, 77, 290 (1993).

9) T.Yasue, Y.Arai, Sekko to Sekkai, No.243, 42 (1993).

10) J.D.Termine, E.D.Eanes, Calc. Tiss. Res., 10, 171 (1972).

11) L.Brecevic, V.Hlady ,H.Furedi-Milhofer, Coll. Surface, 28, 301 (1987).

12.) J.M.Holmes, R.A.Beebe, Calc. Tiss. Res., 7, 163 (1971).

13) L.Brecevic, M.Furedi-Milhofer, Calc. Tiss. Res., 10, 82 (1972).

14) T.Umegaki, S. Yamashita, T.Kanazawa, Sekko to Sekkai, No.183, 11 (1983).

15) Y.Masuda, K.Matsubara, S.Satsuka, Seramikkusu Ronbunshi, 98, 1255 (1982).

16) F.Beets, A.S.Posner, Mat. Res. Bull., 9, 353 (1974).

17) F.Beets, N.C.Blumenthal, A.S.Posner, G.1.Becker, A.L.Lehninger, Proc. Nat. Acad. Sci. U.S.A., 72, 2088 (1975).

18) F.Beets, A.S.Posner, Trans. Am. Crystal. Assoc., 10, 73 (1974).

19) J.M.Sedlak, R.A.Beebe, J. Coll. Inter. Sci., 47, 483 (1974). 